\title{
NOTA
}

\section{EQUIPAMENTO PARA COLETA DE AMOSTRAS INDEFORMADAS DE SOLO PARA ESTUDOS EM CONDIÇÕES CONTROLADAS ${ }^{(1)}$}

\author{
Leandro Bortolon $^{(2)}$, Clesio Gianello ${ }^{(3)}$, Osmar Conte $^{(2)}$, Elisandra \\ Solange Oliveira ${ }^{(2)} \&$ Renato Levien ${ }^{(3)}$
}

\begin{abstract}
RESUMO
A avaliação da fertilidade do solo pode ser feita por vários métodos, entre eles os testes com plantas em campo ou em vasos. Estudos em casa de vegetação com solos sob sistema plantio direto são dificultados pela obtenção de amostras indeformadas. $\mathrm{O}$ presente estudo teve por objetivos propor um equipamento de coleta de amostras de solo indeformadas e testar sua eficácia para uso em estudos em casa de vegetação, especialmente em solos sob sistema plantio direto. Foi desenvolvido um amostrador cilíndrico com diâmetro de 200 e $300 \mathrm{~mm}$ de altura. Foram comparadas a resistência do solo à penetração e a densidade do solo no local de coleta e dentro do amostrador. A amostragem foi feita em quatro locais, em solos com distintas classes de argila e em diferentes profundidades, sendo: um Argissolo Vermelho distrófico típico (PVd) localizado na Estação Experimental Agronômica da UFRGS, em Eldorado do Sul; um Latossolo Vermelho distrófico típico (LVd2) localizado em área de produção, em Cruz Alta; um Latossolo Vermelho distroférrico típico (LVdf2) localizado em área de produção, em Ijuí; e um Latossolo Vermelho distroférrico típico (LVdf2) localizado em área de produção, em São Miguel das Missões. Não houve diferença estatística entre as médias de resistência do solo à penetração e a densidade do solo em cada local e em cada profundidade de amostragem. O equipamento proposto permite obter amostras de solo indeformadas que podem ser utilizadas para estudos em condições controladas com amostras de solo, com estrutura indeformada.
\end{abstract}

Termos de indexação: resistência do solo à penetração, compactação, densidade.

\footnotetext{
(1) Parte da Tese de Doutorado do primeiro autor. Projeto executado com recursos do Projeto Laboratório de Análises de Solos da Universidade Federal do Rio Grande do Sul; CNPq; e Fundação Agrisus - PA 396/07. Recebido para publicação em setembro de 2008 e aprovado em agosto de 2009.

${ }^{(2)}$ Doutorando(a) do Programa de Pós-Graduação em Ciência do Solo, Universidade Federal do Rio Grande do Sul - UFRGS. Av. Bento Gonçalves 7712, CEP 91540-000 Porto Alegre (RS). Bolsista do CNPq. E-mails: leandro.bortolon@ufrgs.br; agroconte@yahoo.com.br; elisandra.oliveira@ufrgs.br

(3) Professor Associado do Departamento de Solos da Faculdade de Agronomia, UFRGS. E-mails: cgianello@hotmail.com; renatole@ufrgs.br
} 


\title{
SUMMARY: UNDISTURBED SOIL SAMPLING EQUIPMENT FOR RESEARCH IN CONTROLLED CONDITIONS
}

\begin{abstract}
Soil fertility can be evaluated by several methods, such as field or greenhouse tests with plants. In greenhouse studies with untilled soils the sampling of undisturbed soil cores is difficult. The aim of this study was to propose an equipment for undisturbed soil core sampling of untilled soils for greenhouse studies and test its efficiency. A sampler with a diameter of $200 \mathrm{~mm}$ and depth of $300 \mathrm{~mm}$ was developed. The soil penetration resistance and density of the soil and within the sampler were compared. Soil was sampled at four sites with different clay contents: an Acrisol, at the UFRGS Agronomic Experimental Station (Lat. S $30^{\circ} 05$ ' 42 " and Long. $W 51^{\circ} 40^{\prime} 32^{\prime \prime}$ ), in Eldorado do Sul; an Oxissol in a crop production area (Lat. S $28^{\circ} 44^{\prime} 17$ " and Long. W $53^{\circ} 41^{\prime} 54$ ") in Cruz Alta; an Oxissol in a crop production area (Lat. S $28^{\circ} 19^{\prime} 55^{\prime}$ " and Long. W $53^{\circ} 55^{\prime} 54$ ") in Ijuí; and an Oxissol in a crop production area in São Miguel das Missões (Lat. S $28^{\circ} 55^{\prime} 53^{\prime}$ "and Long. W $54^{\circ} 20^{\prime} 47$ "). The results did not differ statistically for soil penetration resistance and soil density at each site and sampling depth. The proposed methodology can be used to collect undisturbed soil samples in greenhouse studies with untilled soils.
\end{abstract}

Index terms: soil penetration resistance, compaction, soil bulk density.

\section{INTRODUÇÃO}

A avaliação da fertilidade do solo pode ser feita por vários métodos, entre os quais os testes com plantas em campo ou em vasos. Os testes com plantas cultivadas em vasos, em casas de vegetação, podem ser utilizados para diversos estudos (comparação de fontes de nutrientes, relações solo-planta, estudos de nutrição de plantas, comparações de métodos de análises de solo, dentre outros) (Bissani et al., 2008). Além disso, permitem o estudo simultâneo de um grande número de solos, realizados em qualquer época do ano, com reduzido tempo de duração (semana ou meses) e baixo custo.

O modo de condução desses experimentos representa bem o sistema convencional de cultivo, pois o solo coletado é desagregado, passado em peneira (aproximadamente $5 \mathrm{~mm}$ de abertura) e posteriormente colocado nos vasos. No entanto, esse procedimento dificulta os estudos em vasos com amostras de solos utilizados em sistema plantio direto, pois o revolvimento do solo para o acondicionamento nos vasos altera as suas características físicas (estrutura, porosidade, densidade, agregação, entre outras) (Hillel, 1982). Além disso, alteram a distribuição dos nutrientes, especialmente o $\mathrm{C}$ e o $\mathrm{P}$, que se acumulam na superfície do solo nesse sistema, formando um gradiente de concentração (Anghinoni, 2007; Gatiboni et al., 2007). Nesse caso, avaliações conduzidas em solos sob plantio direto, em vasos, devem preservar ao máximo as condições físicas originais, destacando a importância de coletas de amostras com estrutura indeformada representativas dessas condições.

Dos diversos indicadores do estado físico do solo, sobretudo de compactação, os mais utilizados são a densidade e a resistência mecânica à penetração
(Raper, 2005). Reichert et al. (2003, 2009) definiram limites críticos de densidade do solo de acordo com classes texturais; dessa forma, seria possível inferir o estado de compactação do solo a partir dos valores críticos de densidade do solo. O método-padrão para quantificação da densidade do solo, que envolve a coleta de amostras indeformadas por anéis volumétricos (Embrapa, 1997), é trabalhoso, demorado e destrutivo.

Há vários trabalhos publicados na literatura, com estudos em vasos, utilizando solo sob sistema plantio direto, porém os que utilizaram amostras indeformadas não especificaram o critério adotado para defini-las como tal (Schlindwein et al., 2003; Diekow et al., 2006; Leite et al., 2006; Gatiboni et al., 2007; Rheinheimer et al., 2007; Pavinato \& Rosolem, 2008). O objetivo do presente trabalho foi propor um equipamento de obtenção de amostras indeformadas, de solos sob sistema plantio direto, para estudos em vasos conduzidos sob condições controladas e validação destes pela comparação de alguns atributos físicos do solo nas amostras obtidas e no local de coleta.

\section{MATERIAL E MÉTODOS}

O trabalho foi desenvolvido inicialmente no Laboratório de Análises de Solo da UFRGS. O amostrador foi feito em forma cilíndrica, em aço inoxidável, com as dimensões de $208 \mathrm{~mm}$ de diâmetro externo, $300 \mathrm{~mm}$ de comprimento e $4 \mathrm{~mm}$ de espessura, tendo $200 \mathrm{~mm}$ de diâmetro interno para acoplar um tubo de PVC de $200 \mathrm{~mm}$ de diâmetro (Figura 1). A borda inferior do amostrador foi acabada em formato de bisel, com espessura menor do que $1 \mathrm{~mm}$, e afiada para facilitar a penetração no solo. 


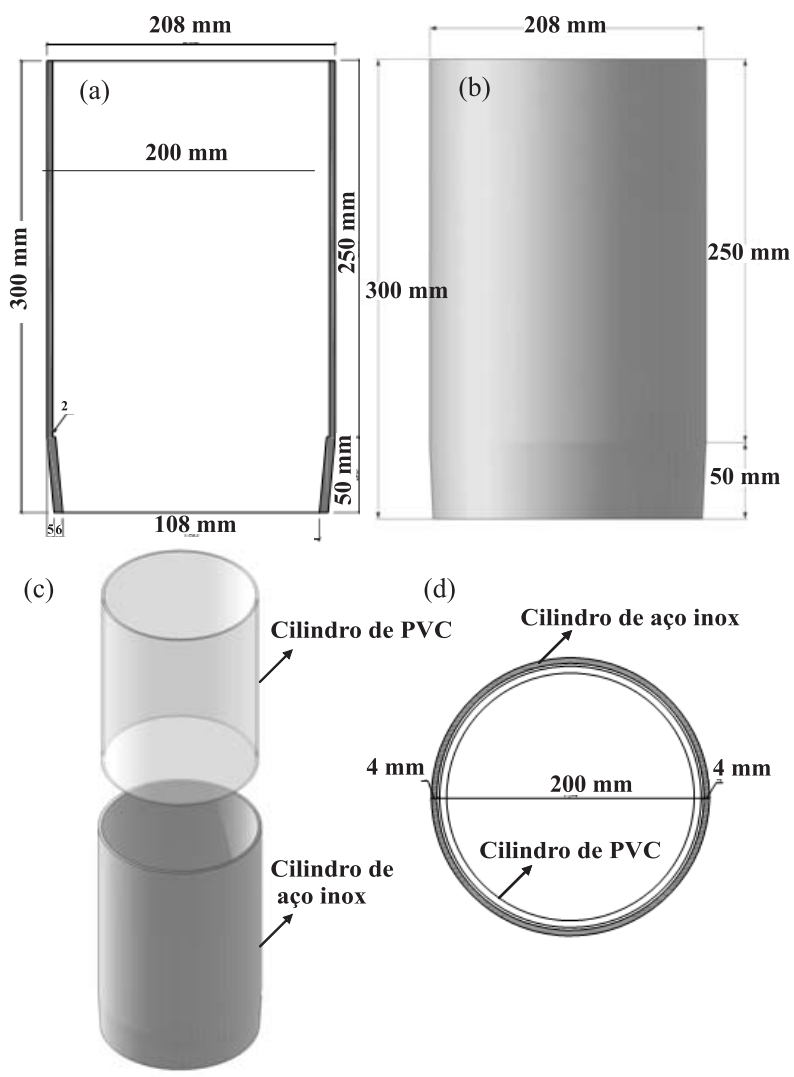

Figura 1. Detalhe do amostrador: corte frontal (a); vista frontal (b); projeção amostrador e PVC (c); e vista superior $(d)$.

Na borda inferior em bisel, com tamanho de $50 \mathrm{~mm}$, foi feita uma sobreposição interna com espessura de $2 \mathrm{~mm}$, para suportar um cilindro de PVC de mesma espessura. Um cilindro de PVC com as dimensões de $200 \mathrm{~mm}$ de diâmetro externo, $250 \mathrm{~mm}$ de profundidade e $2 \mathrm{~mm}$ de espessura foi acoplado dentro do cilindro, de forma que a parte inferior do PVC ficasse apoiada na sobreposição. Dessa maneira, obtém-se a uniformidade entre parede interna do bisel e parede interna do PVC, permitindo a penetração contínua no solo.
Para avaliação do método, foram selecionadas áreas conduzidas em sistema plantio direto, no Estado do Rio Grande do Sul, com mais de 15 anos de adoção, em solos com diferentes teores de argila, num total de quatro locais, sendo: um Argissolo Vermelho distrófico típico (PVd) localizado na Estação Experimental Agronômica da UFRGS (lat. S $30^{\circ} 05$ “ 42 ” e long. O $51^{\circ} 40^{\prime} 32^{\circ}$ "), em Eldorado do Sul; um Latossolo Vermelho distrófico típico (LVd2) localizado em área de produção (lat. S $28^{\circ} 44^{\prime} 17$ " e long. O $53^{\circ} 41^{\prime}$ 54 ”), em Cruz Alta; um Latossolo Vermelho distroférrico típico (LVdf2) localizado em área de

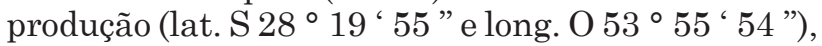
em Ijuí; e um Latossolo Vermelho distroférrico típico (LVdf2) localizado em área de produção, em São Miguel das Missões (lat. S $28^{\circ} 55^{\prime}$ '53” e long. O $54^{\circ} 20^{\prime} 47$ ”) (Quadro 1).

O amostrador foi introduzido no solo por um sistema de levante hidráulico manual (macaco hidráulico tipo garrafa com capacidade de 16 t). Na extremidade superior do cilindro foi colocada uma tampa de aço com diâmetro de $250 \mathrm{~mm}$ e com espessura de $10 \mathrm{~mm}$. O sistema de levante hidráulico manual foi acoplado sobre a tampa do amostrador. Como contrapeso, maior que a resistência do solo, foi utilizado um trator agrícola. O sistema de levante hidráulico manual foi acionado e o amostrador foi então introduzido no solo por pressão lenta e contínua, sem impacto. Previamente, foi passado óleo mineral na parte externa do amostrador, com a finalidade de reduzir o atrito entre o solo e o amostrador. O óleo mineral não entrou em contato com o solo dentro do tubo de PVC - esse procedimento foi adotado para facilitar a introdução do cilindro, principalmente em solos com alto conteúdo de argila e umidade.

Foram introduzidos dois amostradores simultaneamente no solo, utilizando-se dois macacos hidráulicos, um para cada amostrador. Após a introdução completa deles, foi determinada a resistência do solo à penetração (índice de cone) dentro de um dos amostradores e na área adjacente a eles, na profundidade de 0 a $20 \mathrm{~cm}$, com um penetrômetro eletrônico com

Quadro 1. Atributos físicos e químicos dos solos utilizados no estudo, na profundidade de 0-20 cm

\begin{tabular}{|c|c|c|c|c|}
\hline \multirow{4}{*}{ Atributo $^{(1)}$} & \multicolumn{4}{|c|}{ Solo } \\
\hline & PVd & LVd2 & LVdf2 & LVdf2 \\
\hline & \multicolumn{4}{|c|}{ Município de coleta } \\
\hline & Eldorado do Sul & Cruz Alta & Ijuí & São Miguel das Missões \\
\hline Areia $\left(\mathrm{g} \mathrm{kg}^{-1}\right)$ & 530 & 640 & 100 & 190 \\
\hline Silte $\left(\mathrm{g} \mathrm{kg}^{-1}\right)$ & 270 & 280 & 190 & 270 \\
\hline Argila $(\mathrm{g} \mathrm{kg} \cdot 1)$ & 200 & 360 & 710 & 540 \\
\hline $\operatorname{COT}\left(\mathrm{g} \mathrm{kg}^{-1}\right)^{(2)}$ & 21 & 25 & 30 & 23 \\
\hline $\mathrm{pH}$ & 5,2 & 5,3 & 5,5 & 5,2 \\
\hline
\end{tabular}

${ }^{(1)}$ Conforme Tedesco et al. (1995). ${ }^{(2)}$ Carbono orgânico total. 
configurações de acordo com as normas contidas na ASAE 2004. A introdução completa do cilindro foi definida quando a extremidade superior do amostrador ficasse aproximadamente a $1 \mathrm{~cm}$ do nível do solo. Desse modo, evitou-se a compactação da camada superficial pelo contato com a tampa de suporte do sistema de levante hidráulico manual. No outro amostrador, a amostra foi mantida indeformada, para determinação da densidade. Após essa avaliação, o amostrador foi retirado do solo pelo sistema de levante hidráulico do trator agrícola. A retirada do amostrador foi feita acoplando-se uma corrente aos braços do levante hidráulico. Essa corrente, por sua vez, foi acoplada a outra corrente colocada na parte externa do amostrador e fixada a este por meio de um encaixe circular de aço de $10 \mathrm{~mm}$, em duas extremidades do amostrador. A corrente do amostrador possui ajuste de tamanho para acoplá-lo a diferentes modelos de tratores agrícolas (altura de trabalho, ajustes de largura, etc.). A retirada do amostrador foi feita pelo acionamento do sistema hidráulico do trator (levante de três pontos ou equipamento de levante acoplado ao sistema de comando hidráulico), de forma lenta e contínua. Depois disso, foi feita a retirada do tubo de PVC do amostrador, removendo-se o excesso de solo da extremidade inferior $(50 \mathrm{~mm})$, com uma faca. O tubo de PVC foi removido manualmente do amostrador, deslocando-se a parte inferior no sentido da superior. Após a retirada do tubo de PVC, o solo restante na extremidade inferior foi removido com faca, mantendo-se como nível a extremidade inferior do tubo de PVC. Na extremidade superior não é necessário ajuste no volume de solo, pois a introdução no solo é realizada até restar aproximadamente $1 \mathrm{~cm}$ de distância da extremidade superior do cilindro. Para evitar perda de solo na extremidade inferior, foi colocada uma tela de náilon de abertura $<0,3 \mathrm{~mm}$, fixada com atilho de borracha. Durante todo esse processo, foi mantido um ângulo de aproximadamente $30^{\circ}$ na mobilização do amostrador/PVC, para evitar que a superfície do solo fosse mobilizada.
Foram também coletadas amostras indeformadas de solo pelo método do anel volumétrico (Embrapa, 1997) nas profundidades de 0 a 5,0, 5,0 a 10,0, 10,0 a 15,0 e 15,0 a $20,0 \mathrm{~cm}$ na área adjacente de onde o amostrador foi retirado. Foram evitadas nesse caso áreas com tráfego do rodado do trator, bem como as desestruturadas por ocasião da retirada do sistema. No Laboratório de Física do Solo do Departamento de Solos da UFRGS, foi determinada a densidade do solo nas amostras coletadas com o amostrador, em cada local, pelo método do anel volumétrico, conforme recomendações da Embrapa (1997), nas mesmas profundidades avaliadas no campo, bem como o teor de umidade em cada profundidade de amostragem. Para cada local foram feitas quatro repetições de cada avaliação (densidade do solo e resistência do solo à penetração).

A análise estatística dos dados foi feita com o teste t para comparação de médias pareadas, a $1 \%$.

\section{RESULTADOS E DISCUSSÃO}

Os dados de resistência do solo à penetração, expressa em $\mathrm{kPa}$ (índice de cone), e a densidade do solo, em cada classe de solo e em cada profundidade, obtidos no solo e no amostrador, são mostrados nos quadros 2 e 3 . A comparação foi feita em cada solo, na mesma profundidade dos valores médios obtidos das análises físicas no solo e no amostrador proposto.

Não foram obtidas diferenças estatísticas significativas nos valores de resistência do solo à penetração, independentemente do tipo de solo e da profundidade de amostragem (Quadro 2). A compactação do solo reduz o índice de vazios (relação volume de vazios/volume de sólidos) pela reorganização das partículas do solo, quando submetido a uma força de compressão (Costa et al., 2003). A introdução do

Quadro 2. Índice de cone obtido em quatro classes de solo, em duas condições de amostragem para cada solo, calculado em intervalos de 5 a $20 \mathrm{~cm}$ de profundidade

\begin{tabular}{|c|c|c|c|c|c|c|c|c|}
\hline \multirow{3}{*}{ Profundidade } & \multicolumn{8}{|c|}{ Classe de solo } \\
\hline & \multicolumn{2}{|c|}{ PVd } & \multicolumn{2}{|c|}{ LVdf2 } & \multicolumn{2}{|c|}{ LVdf2 } & \multicolumn{2}{|c|}{ LVdf2 } \\
\hline & Amostrador & Solo & Amostrador & Solo & Amostrador & Solo & Amostrador & Solo \\
\hline $\mathrm{cm}$ & \multicolumn{8}{|c|}{ Índice de cone $(\mathrm{kPa})^{(1)}$} \\
\hline $0-5$ & 1.393 & 1.391 & 1.478 & 1.429 & 516 & 605 & 1.699 & 1.802 \\
\hline $5-10$ & 2.040 & 1.600 & 1.923 & 1.746 & 1.199 & 1.334 & 2.634 & 2.597 \\
\hline $10-15$ & 2.175 & 1.655 & 1.965 & 1.989 & 1.856 & 1.629 & 2.194 & 2.335 \\
\hline $15-20$ & 2.079 & 1.901 & 2.048 & 2.088 & 1.946 & 1.783 & 2.220 & 2.381 \\
\hline Média & 1.922 & 1.639 & 1.853 & 1.823 & 1.379 & 1.338 & 2.187 & 2.279 \\
\hline $\mathrm{CV}(\%)$ & 20 & 14 & 13 & 17 & 23 & 24 & 7 & 4 \\
\hline $\mathrm{Ug}\left(\mathrm{kg} \mathrm{kg}^{-1}\right)^{(2)}$ & 0,13 & 0,13 & 0,23 & 0,21 & 0,27 & 0,29 & 0,21 & 0,22 \\
\hline
\end{tabular}

(1) Resistência do solo à penetração, expressa em índice de cone $(\mathrm{kPa}) .{ }^{(2)} \mathrm{Ug}$ : umidade gravimétrica. 
Quadro 3. Densidade do solo obtida em quatro classes de solo, em duas condições de amostragem para cada solo, em intervalos de 5 a $20 \mathrm{~cm}$ de profundidade

\begin{tabular}{|c|c|c|c|c|c|c|c|c|}
\hline \multirow{3}{*}{ Profundidade } & \multicolumn{8}{|c|}{ Classe de solo } \\
\hline & \multicolumn{2}{|l|}{ PVd } & \multicolumn{2}{|l|}{ LVd2 } & \multicolumn{2}{|l|}{ LVdf2 } & \multicolumn{2}{|l|}{ LVdf2 } \\
\hline & Amostrador & Solo & Amostrador & Solo & Amostrador & Solo & Amostrador & Solo \\
\hline $\mathrm{cm}$ & \multicolumn{8}{|c|}{ Densidade do solo $\left(\mathrm{Mg} \mathrm{m}^{-3}\right)^{(1)}$} \\
\hline $0-5$ & 1,41 & 1,51 & 1,48 & 1,54 & 1,18 & 1,15 & 1,27 & 1,32 \\
\hline $5-10$ & 1,50 & 1,57 & 1,47 & 1,55 & 1,28 & 1,27 & 1,41 & 1,42 \\
\hline $10-15$ & 1,53 & 1,62 & 1,50 & 1,50 & 1,32 & 1,25 & 1,42 & 1,43 \\
\hline $15-20$ & 1,55 & 1,63 & 1,50 & 1,51 & 1,30 & 1,24 & 1,42 & 1,44 \\
\hline Média & 1,50 & 1,58 & 1,49 & 1,53 & 1,27 & 1,23 & 1,38 & 1,40 \\
\hline $\mathrm{CV}(\%)$ & 4 & 4 & 5 & 3 & 8 & 6 & 5 & 4 \\
\hline $\mathrm{Ug}\left(\mathrm{kg} \mathrm{kg}^{-1}\right)^{(2)}$ & 0,13 & 0,13 & 0,23 & 0,21 & 0,27 & 0,29 & 0,21 & 0,22 \\
\hline
\end{tabular}

(1) Densidade do solo $\mathrm{Mg} \mathrm{m}^{-3}$. ${ }^{(2)} \mathrm{Ug}$ : umidade gravimétrica.

amostrador no solo não causou a sua compactação, possivelmente em razão de o modo de introdução dele ser por pressão lenta e contínua, sem impacto. Alterações na estrutura física das amostras podem ocorrer próximo da parede do cilindro, devido à reacomodação nas partículas de solo e à entrada do amostrador no perfil do solo. A introdução do amostrador no solo por impacto, possivelmente, favoreceria a desestruturação do solo e o rearranjo das suas partículas, modificando os valores de resistência deste à penetração e densidade. A mesma tendência foi observada em todos os solos, independentemente da classe textural. Desse modo, o método de obtenção de amostras indeformadas com uso do equipamento proposto em áreas sob plantio direto pode ser utilizado em solos com diferentes classes texturais.

Os valores de densidade do solo obtidos em cada condição são mostrados no quadro 3. Não foram observadas diferenças estatísticas significativas nas condições estudadas. O rearranjo das partículas do solo pela acomodação natural de partículas e pelo tráfego contínuo de máquinas e implementos na sua superfície ou pelo impacto direto resulta em aumento da densidade do solo e modificações no sistema poroso (Hillel, 1982; Costa et al., 2003), bem como em aumento na resistência do solo à penetração (Costa et al., 2003). A introdução do equipamento no solo, por ser feita por pressão lenta e contínua, não modifica os valores de densidade do solo, independentemente da classe textural.

Quanto à obtenção de amostras por meio do amostrador proposto, notou-se boa eficiência e agilidade no processo, com poucos eventos de descarte de amostras por problemas. Um dos maiores cuidados na utilização é com relação à introdução do cilindro metálico, que deve permanecer exatamente na posição vertical, a fim de evitar inclinações durante penetração no solo - que, se acaso ocorrer, tornará necessário reiniciar o processo. Devido à boa resistência do metal e à borda em bisel, não foram observados problemas quanto à presença de raízes na coleta em áreas agrícolas. Possivelmente, isso seria uma limitação para uso em coletas onde houvesse vegetação arbustiva ou florestas, em que o diâmetro das raízes é maior. O mesmo impedimento pode ocorrer em solos com textura grosseira, com presença de cascalho e calhaus, ou então em rochas, as quais poderiam ser um entrave à introdução do cilindro no perfil, ou então danificando a borda em bisel e causando desvio no ângulo de introdução. Em solo com elevado teor de argila e, principalmente, se houver argilominerais expansíveis, na condição de umidade elevada do solo, a obtenção de amostras pode ser dificultada ou até impedida pela adesão solo-metal. Recomenda-se a coleta quando o teor de água no solo estiver abaixo do limite inferior de plasticidade, para permitir boas condições de trabalho.

Neste estudo, avaliou-se a eficácia do amostrador na obtenção de amostras indeformadas em sistema plantio direto justamente pela dificuldade de simular as condições de estrutura de solo encontradas em campo, mas isso não restringe sua aplicação somente nessas situações. Seu uso para amostragem em sistema convencional de preparo de solo é possível, e provavelmente o processo seja mais ágil devido à menor resistência à introdução no perfil do solo. Nesse caso, apresentaria a vantagem de manter a estrutura em termos de não mistura de camadas de solo de interesse, podendo as amostras ser dispostas para cultivo assim como são obtidas no campo. Como isso não foi avaliado nessas condições, seriam necessários estudos de adequação de uso ou ao menos comprovar se essa técnica é mais eficiente em termos de agilidade na amostragem, visto que a integridade estrutural das amostras, nesse caso, é menos relevante. 


\section{CONCLUSÃO}

O equipamento proposto é eficiente para obtenção de amostras indeformadas de solos, não tendo alterado a densidade e a resistência do solo à penetração em sistema plantio direto, podendo ser usado para estudos em condições controladas.

\section{AGRADECIMENTOS}

Ao Projeto Laboratório de Análises de Solo da UFRGS, ao CNPq e à Fundação Agrisus (PA 396/07), pelo apoio financeiro destinado ao estudo; à arquiteta Alessandra Gianello, pelo desenho do projeto; e, principalmente, à disponibilidade dos produtores Adelar Nicolodi (Cruz Alta), Cabanha Cerro Coroado (São Miguel das Missões) e Luiz Koslowski (Ijuí), por cederem suas áreas para coleta das amostras e pelo apoio indispensável para a execução deste trabalho.

\section{LITERATURA CITADA}

ANGHINONI, I. Fertilidade do solo e seu manejo em sistema plantio direto. In: NOVAIS, R.F.; ALVAREZ V., V.H.; BARROS, N.F.; FONTES, R.L.F.F.; CANTARUTTI, R.B. \& NEVES, J.C.L., eds. Fertilidade do solo. Viçosa, MG, Sociedade Brasileira de Ciência do Solo, 2007. p.873-928.

AMERICAN SOCIETY OF AGRICULTURAL ENGINEERS ASAE. Soil Cone Penetrometer-ASAE S313.3. Saint Joseph, 2004.

BISSANI, C.A.; CAMARGO, F.A.O.; GAINELlO, C. \& TEDESCO, M.J. Fertilidade dos solos e manejo da adubação de culturas. 2.ed. Porto Alegre, Metrópole, 2008. $344 \mathrm{p}$.

COSTA, F.S.; ALBUQUERQUE, J.A.; BAYER, C.; FONTOURA, S.M.V. \& WOBETO, C. Propriedades físicas de um Latossolo Bruno afetadas pelos sistemas plantio direto e preparo convencional. R. Bras. Ci. Solo, 27:527$535,2003$.

DIECKOW, J.; MEURER, E.J. \& SALET, R.L. Nitrogen application timing and soil inorganic nitrogen dynamics under no-till oat/maize sequential cropping. R. Bras. Ci. Solo, 30:707-714, 2006.
EMPRESA BRASILEIRA DE PESQUISA AGROPECUÁRIA EMBRAPA. Centro Nacional de Pesquisa de Solos. Manual de métodos e análise de solo. 2.ed. Rio de Janeiro, 1997. $212 p$.

GATIBONI, L.C.; KAMINSKI, J.; RHEINHEIMER, D.S. \& FLORES, J.P.C. Biodisponibilidade de formas de fósforo acumuladas em solo sob sistema plantio direto. R. Bras. Ci. Solo, 31:691-699, 2007.

HILLEL, D. Introduction to soil physics. New York, Academic Press, 1982. 364p.

LEITE, P.B.; ALVAREZ V., V.H.; BARROS, N.F.; NEVES, J.C.L. \& MARTINS, A.G. Níveis críticos de fósforo, para milho, em casa de vegetação, de acordo com a sua localização no solo. R. Bras. Ci. Solo, 30:497-508, 2006.

PAVINATO, P.S. \& ROSOLEM, C.A. Disponibilidade de nutrientes no solo - decomposição e liberação de compostos orgânicos de resíduos vegetais. R. Bras. Ci. Solo, 32:911920,2008

RAPER, R.L. Agricultural traffic impacts on soil. J. Terramechanics, 42:259-280, 2005.

REICHERT, J.M.; REINERT, D.J. \& BRAIDA, J.A. Manejo, qualidade do solo e sustentabilidade: Condições físicas do solo agrícola. In: CONGRESSO BRASILEIRO DE CIÊNCIA DO SOLO, 29., Ribeirão Preto, 2003. Anais. Ribeirão Preto, Sociedade Brasileira de Ciência do Solo, 2003. CD ROM.

REICHERT, J.M.; SUZUKI, L.E.A.S.; REINERT, D.J.; HORN, R. \& HAKANSSON, I. Reference bulk density and critical degree-of-compactness for no-till crop production in subtropical highly weathered soils. Soil Tillage Res., 102:242-254, 2009.

RHEINHEIMER, D.S.; ALVAREZ, J.R.; OSÓRIO FILHO, B. \& SOUSA, L.S. Resposta à aplicação e recuperação de enxofre em cultivos de casa de vegetação em solos com diferentes teores de argila e matéria orgânica. Ci. Rural, 37:363-371, 2007.

SCHLINDWEIN, J.A.; NOLLA, A.; ANGHINONI, I. \& MEURER, E.J. Redução da toxidez de alumínio em raízes de soja por culturas antecessoras no Plantio Direto. R. Bras. Agroci., 9:85-88, 2003.

TEDESCO, M.J.; GIANELLO, C.; BISSANI, C.A.; BOHNEN, H. \& VOLKWEISS, S.J. Análise de solo, plantas e outros materiais. 2.ed. Porto Alegre, Universidade Federal do Rio Grande do Sul, 1995. 147p. (Boletim Técnico, 5) 